\title{
FREEDERICKSZ MEDALS FOR THE OUTSTANDING RESULTS IN THE FIELD OF LIQUID CRYSTAL PHYSICS AND CHEMISTRY IN 2017
}

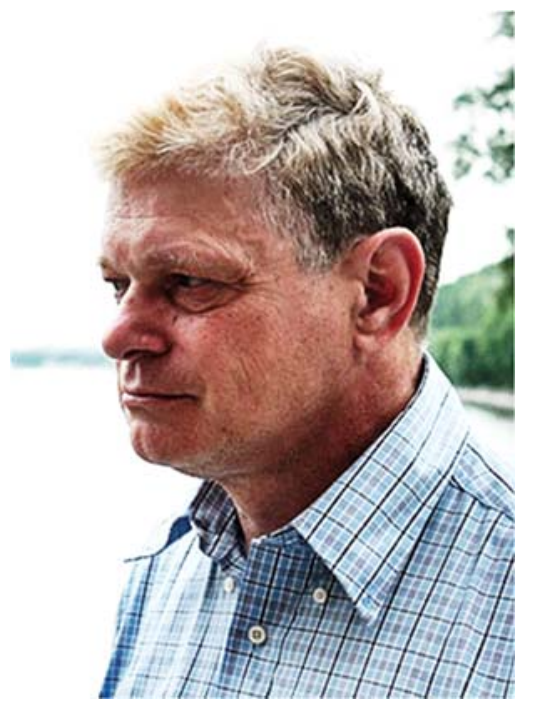

\section{Professor Osipov Mikhail Alekseevich}

Mikhail Osipov graduated from the Physics Faculty of Moscow State University in 1979, and in 1983 defended his Ph.D. thesis. In the period 1983-2000 he worked in the theoretical department of the Institute of Crystallography of the Russian Academy of Sciences and in 1991 defended his doctoral dissertation on the theory of condensed state.

Since 2000, M. Osipov has been working as a professor of applied mathematics at Stracheide University in the United Kingdom, where in 2000-2009, was the leader of the group of continuum mechanics, which was headed by Professor F. Leslie, a world-famous expert in the field of the mathematical theory of liquid crystals.

Since 2015, M. Osipov also works as the main scientist researcher of the A.V. Topchiev Institute of Petrochemical Synthesis of the Russian Academy of Sciences.
Professor Osipov is one of the leading experts in the world in the field of molecular theory of liquid crystals and related materials. He published more than 150 scientific articles and 8 reviews. M. Osipov made an important contribution to the theory of ferroelectric liquid crystals, the molecular theory of phase transitions in liquid crystals, the theory of elasticity, viscosity, flexoelectric, dielectric and surface properties of liquid crystals, the theory of cholesteric ordering in lowmolecular LC and liquid-crystal polymers, and in recent years also in the molecular theory of liquid-crystalline and polymeric nanocomposites.

Osipov is an active member of the International Liquid Crystal Community. In the period 2006-2011 he was a member of the editorial board of the international journal "Liquid Crystals", and in 2010 he was elected as a member of the Award Committee of this community, where he is currently working. At various stages, Osipov was a member of the International Organizing Committees and Program Committees of International and European Conferences on LCD, as well as International Conferences on ferroelectric LCDs. Since 2018, he is a member of the Newton Fund Commission in the United Kingdom. Professor Osipov regularly presents invited talks and lectures at International Conferences and Schools. In 2008, he was a visiting Mercator professor at the University of Stuttgart with the financial support of the German Scientific Foundation (DFG), which nominated him for this position. Mikhail Osipov was also a visiting professor at the Technical University of Chalmers (Sweden, 1998) and the University of Montpellier II (France, 2007). In the period from 1991-1999. he was a Fellow of the Humboldt Foundation and the Science Foundation of Japan, and also worked at the Tokyo Institute of Technology and at the universities of Southampton, Exeter and Lisbon as a visiting researcher. M. Osipov was one of the organizers of the six-month scientific school "Mathematics of liquid crystals", conducted at the Newton Institute in Cambridge in 2103. In 2015, M. Osipov was awarded the British Liquid Crystal Society medal for outstanding achievements in molecular LC theory.

During his time at Stracchkayd University, M. Osipov was the head of several projects supported by the UK Science Foundation (EPSRC), including a project that forms part of a large international project within the "Materials World network", which was cofinanced by the funds of the United States, Germany, Great Britain, Canada and Sweden (2010-2013). In the period 2009-2013. Mikhail Osipov also directed three projects of the Ministry of Education and Science of the Russian Federation, coordinating the work of the experimental group at the Institute of Petrochemical Synthesis of the Russian Academy of Sciences. Currently, M. Osipov is the head of the project of the Russian Scientific Foundation "Influence of anisotropy on the phase structure and properties of composites based on amorphous and liquid crystal block copolymers and nanoparticles". 


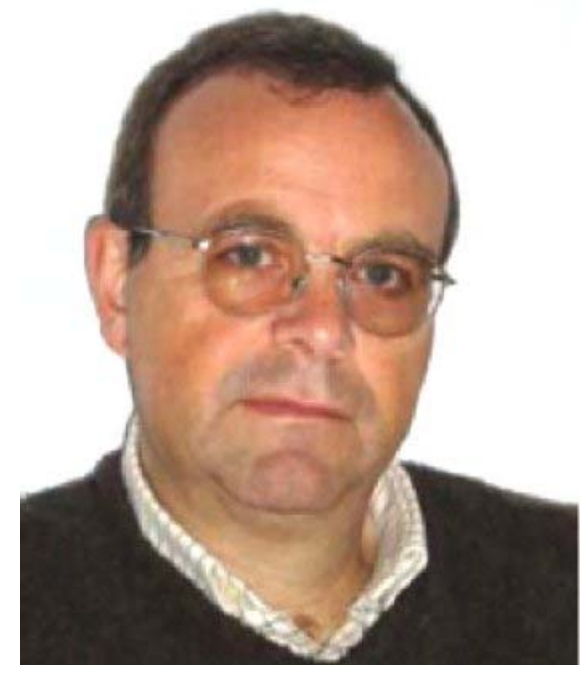

Since the presentation of his doctoral thesis in 1980, he participated together with Professor Enrique Meléndez in the creation of a research group in the University of Zaragoza on the topic of Liquid Crystals (LC), which has gained international recognition, developing several research lines that have been leaders in the field: Ferroelectric and Antiferroelectric, Metalcontaining LC, Photosensitive LC Polymers, LC based on Supramolecular Complexes, Functional LC and more recently in New Materials based on LC Dendrimers and Nanomaterials for Biomedical applications.

Since 1984, he is the group leader of the research group "Liquid Crystals and Polymers" (CLIP) recognized with the highest recognition levels by the Government of Aragon since 2003.

Professor Serrano is editor of the book "Metallomesogens: Synthesis, properties and Applications" VCH, Weinheim (Alemania), 1996. ISBN: 3-527-29296-9. (Authors: M. Marcos, J. Barberá, B. Ros, L. Oriol, P. Alonso, J. L. Serrano).

Up to date, the results of his research activity are collected in more than 350 publications (>285 Q1) (including 13 reviews by invitation), 5 international patents and numerous participations in specialized conferences having given 10 plenary and 36 invited lectures.

Participation in more than 80 lectures and seminars in universities and national and international research centers.

\section{Professor Jose Luis Serrano}

José Luis Serrano received his PhD in Chemistry of Liquid Crystals (CL) in 1980 from the University of Zaragoza (Spain) under the supervision of Prof. Enrique Meléndez (1980). He was appointed as Associate Professor of Organic Chemistry from 1985 to 1996 and, later as full Professor of Organic Chemistry since 1996.

He participated in 27 national projects, being the main researcher in fourteen of them, in 10 European research projects, being coordinator in three of them and principal investigator of the Zaragoza group in the remaining seven projects, and in 20 regional projects, being principal investigator in fifteen of them.

Supervisor of more than 30 doctoral theses, and more than 50 works of initiation to the research in Chemistry (dissertations or analogous dissertations, master's thesis etc.).

Supervisor of 15 postdoctoral researchers from Germany, the United Kingdom, Italy, France, Ireland, Holland, Japan, Chile and Spain.

Participation in evaluation committees of the ANEP, the Scientific and Technological Promotion Agency of Argentina, the FONDECYT Foundation of Chile, the projects of the "TU High-Tech Materials Research Program" of the Technological University of Eindhoven (Netherlands) and projects of the Foundation for Polish Science (Warszawa, Poland).

Visiting professor at the Universities of Sheffield (UK) in 1998 and Bayreuth (Germany) in 2002.

Academic positions: Deputy Director of the Institute of Materials Science of Aragon from 1987 to 1991, Director of the Dept. of Organic Chemistry from 2002 to 2004 and Deputy Director of the Aragon Nanoscience Institute from 2004 to 2007.

From 2007 to 2011 he had the position of General Director of Research, Development and Innovation of the Government of Aragon.

\section{Awards}

"Aragón Investiga" Award 2006 for Excellence in Research.

Scientific secretary of LC Society «Sodruzhestvo» Sofia Torgova 